\title{
Preliminary Quantification of the Passive Role of Solar Rooftop Shading in Bahrain: Towards Energy Reduction for Cooling and Energy Resilience
}

\section{Joao Pinelo Silva1,4, AbdulMajeed AbdulKarim², Shaker Haji³, Motaz Mestarehi4, and Sónia Lamela1,4}

${ }^{1}$ Department of Architecture and Interior Design, University of Bahrain, Kingdom of Bahrain, P.O. Box 32038

${ }^{2}$ Office of Minister of Oil, National Oil and Gas Authority, Kingdom of Bahrain, P.O. Box 1435 ${ }^{3}$ Department of Chemical Engineering, University of Bahrain, Kingdom of Bahrain, P.O. Box 32038

${ }^{4}$ Built Environment Laboratory, University of Bahrain, Kingdom of Bahrain, P.O. Box 32038

\section{Abstract}

Corresponding Author:

Joao Pinelo Silva

jpinelo@edu.uob.bh

Received: 18 September 2018

Accepted: 10 October 2018

Published: 15 October 2018

Publishing services provided by Knowledge $\mathrm{E}$

(c) Joao Pinelo Silva et al. This article is distributed under the terms of the Creative Commons

Attribution License, which permits unrestricted use and redistribution provided that the original author and source are credited.

Selection and Peer-review under the responsibility of the Sustainability and Resilience Conference Committee.
The use of roof-mounted PV photovoltaic panels on building roofs is commonplace. Their operating performance, regarding energy production, has been welldocumented, leading to reasonable predictions of critical economic indices such as the levelised cost of electricity (LCOE), the payback period, and the return on investment (ROI). However, such installations can have a further passive role, which is reducing the solar heat penetration (heat gain) to the building by shading the top exposed roof slab. This article quantifies the added role of PV panel shading in a standard housing typology in Bahrain by estimating the amount of energy that does not penetrate the building due to the shading effects and calculating the resulting reduction of the annual energy consumed by the house. Depending on the efficiency of the cooling system installed, shading one single roof slab can reduce the annual energy consumption by up to $7 \%$. The benefits of such added energy efficiency can be considered in the calculations of the project economics, making such investments more attractive and therefore increasing their adoption rate.

\section{Keywords: Heat Gain, Solar Analysis, Photovoltaic, MENA, Roof, Shading}

\section{Introduction}

The National Oil \& Gas Authority (NOGA) in Bahrain initiated a pilot project to investigate the optimum design criteria and requirements of installing rooftop solar system on typical Government built social housing system - referred to in this paper as type 
T8 Ministry of Housing $(\mathrm{MoH})$ design. The economics of this initiative was initially determined based on the LCOE which can be realistically achieved in Bahrain, with the launching of Bahrain's "National Renewable Energy Action Plan" (NREAP). The focus of the pilot project was to quantify accurately the cumulative government benefits in terms of "energy avoided" from thermal plants, the quantification of gas saving and the carbon emissions. Phase 1 of this pilot project is presently being commissioned at the time of writing this paper, while phase II is presently underway in the tendering and evaluation stage. Different locations have been chosen to implement the pilot, and various PV technologies will be tested in the different phases. During the course of the project, further investigations were initiated between NOGA and the University of Bahrain to quantify the added benefits of enhancing energy efficiency due to rooftop shading and concrete slab heat penetration shielding. Although these investigations are far from being a fully comprehensive exercise, the results are encouraging, and therefore the team decided to share them regionally, through this publication.

Photovoltaic systems (PV) are widely used for the production of electricity. The performance of $\mathrm{PV}$ installations is commonly measured by the annual energy yield at the specific location of the installation, which constitutes the active role of the panels. Nonetheless, when these are used in architecture, as in appended to buildings, they might have added passive roles in the overall energy efficiency equation. Passive effects may contribute to the energetic and thermal performances of buildings. As far as the team is aware, the role of shading from direct solar radiation has not yet been studied in the MENA region. Nevertheless, in the Gulf, this effect might be substantial due to the hot climate and particularly the wide use of flat concrete roof slab and could be potentially relevant.

Several heat mitigation strategies for roofs of building are documented in the specialized literature. Roofs that use such strategies are commonly called 'cool roofs'. Cool roofs use materials and components characterized by high reflectance and consequently the roof surface only reaches a slightly higher temperature than the environment. Several cool roof solutions have been documented and their performance measured. Cool paint (albedo roofs) and mass/reflective insulation are passive cool roof strategies [1]. Other passive solutions that contribute to reduce heat-gain and therefore energy load for cooling are roof ventilation and green roofs [1].

The effects of cool paint on flat concrete roofs was studied on nine different types of houses in Florida, Unites States, resulting on 19\% average savings on the energy consumption of air- 
conditioners (varying between $2 \%$ and $42 \%$ )[2]. Cool paint, when applied to one non- residential building with a high ratio of roof surface to building volume (a vulnerability in terms of heat gain/loss through roof) in a Mediterranean climate, resulted in savings of $54 \%$ of cooling energy demand as a consequence of a decrease of roof surface of $20^{\circ} \mathrm{C}$, during the summer[3]. The degradation of the reflectivity over time of solar exposure has a negative effect on the performance of cool paint [2]; furthermore, reflective surfaces tend to be wet due to slow heating surfaces [2].

Ventilated roof components have an air gap between outward and inward layers. A six centimetre air gap reduced daily heat gain during the summer by $56 \%$, reaching $68 \%$ with additional radiant heat barrier [4], in a study in Greece. The optimum air gap for roofs with 30-900 inclinations is $10 \mathrm{~cm}$ [1]. However, ventilated roofs can be structurally challenging, they require cautious design considerations as the outer layer needs to be sturdy enough to resist various wind forces, but cannot exceed the load bearing capacity of the main roof[1]. Green roofs consist of a planting cover. A rooftop lawn reduced the peak air temperature in a concrete building by 3-40 C in the summer in Japan [5].

Polyethylene insulation, when added to a roof can mitigate heat exchange. Adding a $2.5 \mathrm{~cm}$ thick layer of polyethylene insulation on a scaled concrete roof resulted in a reduced roof soffit temperature by 90 C [6]. Prototype thermal performance measured in laboratory has suggests that a combined application of aluminum reflector along with polyethylene insulation offered a significant heat flux reduction compared with other non-insulated roof prototypes [1].

A detailed understanding of the building physics of local buildings, within the local climate, is paramount for the local population to maintain high levels of thermal comfort while following industry standards[7]. Experimentation with known techniques, such as those briefly described above, as well as new ones, created to the specificities of the region, can lead to more efficient, less energy demanding buildings. Such architectural efforts could complement urban planning ones [8].

\section{Regional Background}

The Government of Bahrain approved the mechanism of "Net-Metering" to support the expansion of renewable energies in the total energy equation in Bahrain. The Minister of Electricity and Water Affairs issued the National Order no. 2 for the year 2017 published on December 28th, 2017 in the official Gazette issue number 3346, paving the way forward for the expansion of distributed renewable energy particularly 
solar energy in Bahrain. Another study [9] has reported considerable benefits of the introduction of a feed-in tariff (FIT) as an alternative support for distributed renewable energy in Bahrain. The Government is actively pursuing the option of "Tendered based Feed in Tariff" for Government owned solar rooftops. Furthermore, it seems logical that a spatially distributed production could offer resilience to the electrical grid.

Bahrain has a large and expanding stock of four-bedroom "social housing" - semidetached houses, such as the typical contemporary model $\mathrm{T} 8$ developed by the Ministry of Housing, which is the object of this paper. The annual energy consumption of such units was quantified to be on average $39,000 \mathrm{kWh}$ per annum, a significant part of which is used for cooling during the summer. These units are typically inhabited by 6 to 9 residents. Ten of these houses, which were distributed to their owners in 2013 and 2014, were chosen for the purpose of the pilot rooftop solar system project. The system is composed of 24 polycrystalline panels, with 72 cells each, for a total annual energy output of $12,500 \mathrm{kWh}$, corresponding to roughly one third of the energy demand of the house. A study was initiated to measure the possible cooling effect of shading on housing rooftops, aiming at quantifying its possible impact on energy demand for cooling. Starting with the design initially proposed, we created several alternatives that increased the shading and analysed each, as summarized in Figure 1.

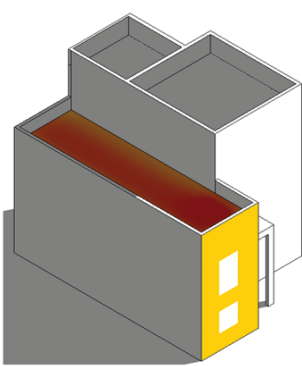

a)

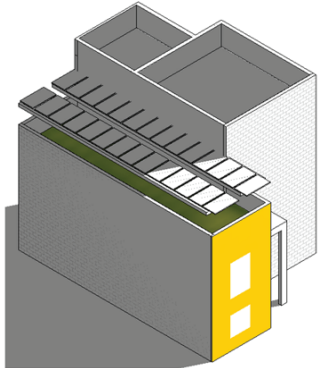

b)

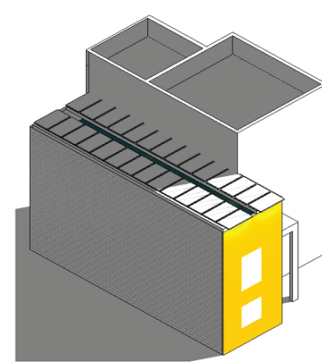

c)

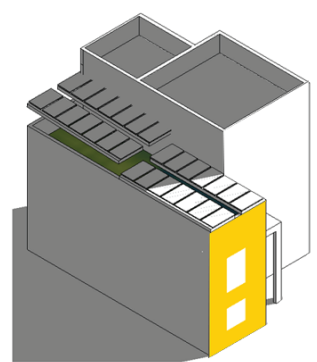

d)
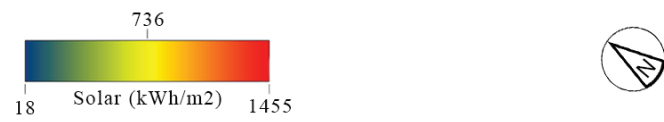

Figure 1: Four perspectives of the T8 house with different shading solutions. a) Original house, no PV (no shading); b) shading as originally proposed; c) most comprehensive shading; d) proposed solution as a compromise between shading and wider utility of the rooftop.

\section{Method}

We took two approaches to investigate the potential role of shading, a) numerical analysis via computer models, and measurements, albeit limited as described below 
on limitations to the study. We created several SketchUp ${ }^{\circledR}$ three dimensional (3D) digital models of the building, to include several iterations of the design solutions for shading, aiming at identifying the one which would reduce the solar exposure the most. The geolocation of the model was set to the geometrical centre of mainland Bahrain, and the orientation set with main entrance to the South. The SketchUp ${ }^{\circledR} 2016$ files were saved as version SKP 6 in order to be exported to Autodesk Revit ${ }^{\circledR} 2017$ as mass models. The solar analysis was performed in Revit, with plugin Insight $360^{\circledR}$ (1.12). The period of analysis was set to a full year (January 1st to December 31st 2017). The solar analysis of all building iterations was run independently, although using the same custom colour-range scale for direct visual comparison across solutions. The solar analysis revealed the cumulative annual insulation on the building and individually on each component (each wall, roof, etc.), considering building orientation, translation and rotation of the earth, as well as the shading of building components (such as roof parapet around roof slab). The analysis of the models allowed for a) the comparison of the predicted annual cumulative insolation across arrangements for the installation of PVs, and b) the identification of the highest density of insolation, confirming the roof as a good candidate to study the effect of shading, due to the significance of the potential outcome.

We measured the solar gain through the slab for three summer days1, summarized in Table 1 and Figure 2, and estimated the heat gain for the summer based on Fourier's law of thermal conduction. The transient heat transfer under direct sun light was estimated based on Equation 1.

$$
\Phi=U A \Delta T
$$

$\mathrm{U}=\mathrm{U}$-value of the building material, in this case the hollow core concrete slab with $150 \mathrm{~mm}$ thickness, in $\mathrm{W} / \mathrm{m}^{2} \mathrm{~K}$. The $\mathrm{U}$-value used was $3.0 \mathrm{~W} / \mathrm{m}^{2} \mathrm{~K}$.

$A=$ Area of the slab in $\mathrm{m}^{2}$. The area used was $56 \mathrm{~m}^{2}$.

$\Delta t=t e-t i$, the difference in temperature between the exterior and interior faces of the wall. The delta temperature used was $30^{\circ} \mathrm{C} ; 53^{\circ} \mathrm{C}$ on the exterior face and $23^{\circ} \mathrm{C}$ on the interior face (Roof slab temperature measurements taken with infrared pyrometer Peak Meter PM6530D, throughout daylight hours, every two hours, at three EastWest points on the roof slab. Please see Table 1.) (with air conditioning) based on the measurements made (See table 1). Roof slab temperature measurements taken with infrared pyrometer Peak Meter PM6530D. 
TABLE 1: Temperature data for three days of temperature survey of roof and ceiling.

Variation of Concrete Slab Temperature Between 6:00 and 18:00 on Three Late-Summer Days in Bahrain (Temperature values in Degrees Celsius)

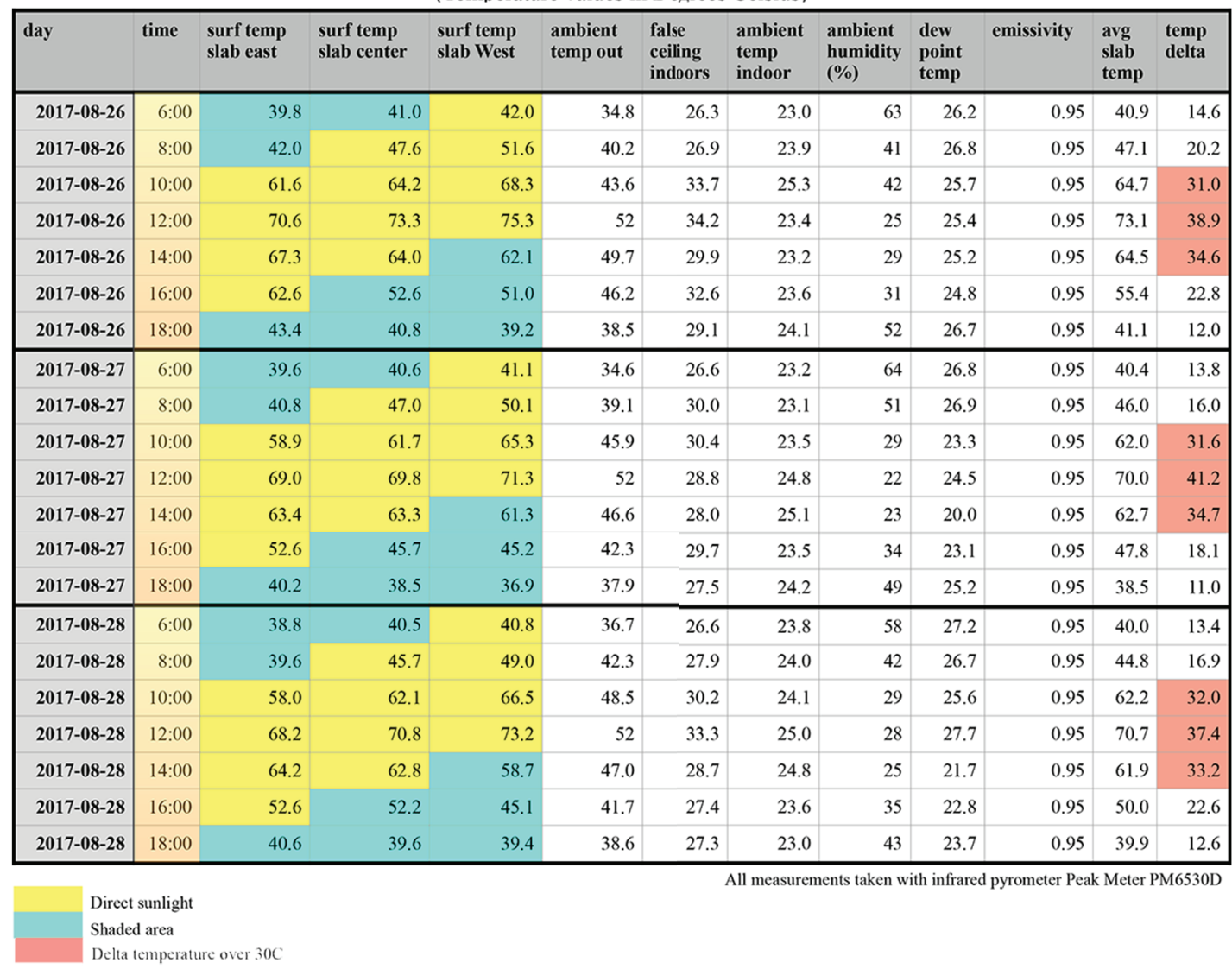

\section{Results}

Numerical modelling reveals that:

- The annual exposure of each house to solar energy is $493,000 \mathrm{kWh} / \mathrm{Year}$;

- The rooftop solar area of $55 \mathrm{~m}^{2}$ roof of bedrooms is exposed to $57,642 \mathrm{kWh} /$ Year;

- The smaller component of the main façade is exposed to $24,645 \mathrm{kWh} / Y e a r$ (when facing South);

- The highest density of insolation is on the roof.

An initial numerical analysis has shown a reduction of $58 \%$ on the annual cumulative insolation on the roof and south-facing facade when shaded by solar panels. An empirical experiment has shown that the shading of the roof alone could reduce the annual energy demand of the dwelling by 2 to $7 \%$.

Based on the calculation of Equation 1, the heat transferred $(\Phi)$ per hour was 5040 W. According to our temperature measurements, the delta of the temperature remains 

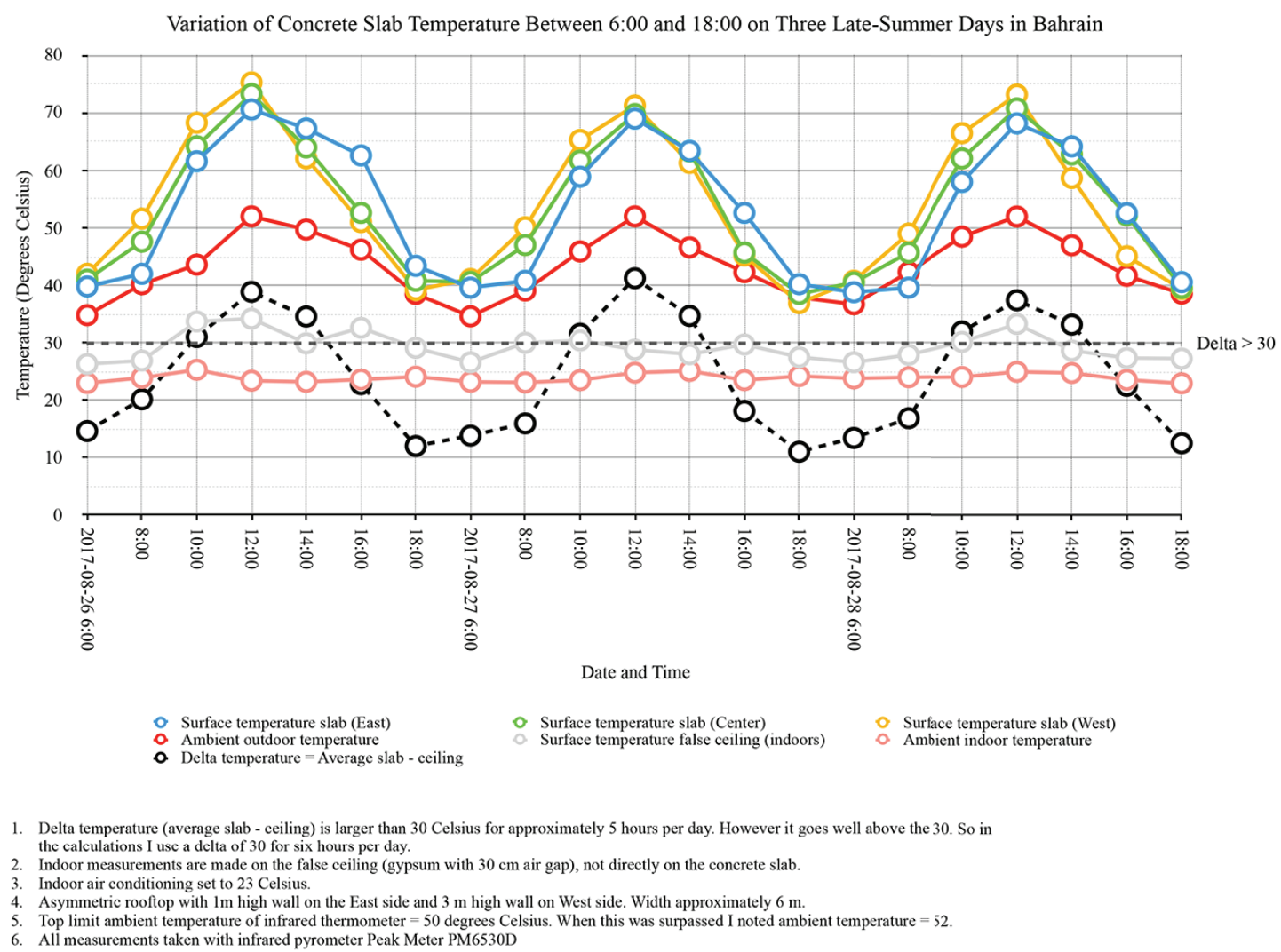

Figure 2: Daily pattern of variation of temperature on roof slab (outdoors and indoors). Notice the delta between indoors and outdoors temperature above $30^{\circ} \mathrm{C}$.

over $30^{\circ} \mathrm{C}$ for approximately 6 hours per day, which implies $30.3 \mathrm{kWh}$ of solar gain per day. When multiplied by 180 days (six warmest months), the total summer transient heat transferred indoors via the roof slab studied is $5443.2 \mathrm{kWh}$. Comparatively, the total transient heat transfer in the shade (delta temperature of $15^{\circ} \mathrm{C}$ ) is of $2721.6 \mathrm{kWh}$, or $50 \%$ of the energy when compared to the slab directly exposed to sunlight.

Considering a contemporary split air conditioning (AC) unit with a coefficient of performance (COP) of 4 , the amount of energy saved on cooling as a consequence of shading the roof slab would be $680 \mathrm{kWh}$, or $1.74 \%$ of the annual energy consumption of the housing unit, which is $39,000 \mathrm{kWh}$. In a real scenario, where a significant proportion of the housing stock has older, less performant, AC units, the savings could be more substantial. For example, for a COP of 2 , the savings would double, to $3.49 \%$, while for a COP of 1 , the savings would be of approximately $7 \%$. As far as we are aware, the average COP of the housing stock is not known. 


\section{Limitations of the Study}

This pilot study was conceived as an exploratory research to measure the potential of the role of shading buildings, considering the warm regional climate and type of construction. This work was necessary to assess the potential value of a thorough study of the topic versus the costs of the necessary setup. Therefore, it is not as thorough as it would be desirable for comprehensively documenting the effects studied. Nonetheless, the results are encouraging, and we therefore decided to make them public via this regional presentation/publication.

Slab temperature was sampled for three days only, every two hours during daytime, rather than quasi-continuous readings for a year, or at least the summer period. The temperature was measured via handheld infrared pyrometer, rather than k-type thermocouples (physical sensors) embedded on the slab. The spatial sampling was done on three places, rather than a comprehensive grid of perhaps six to nine sensors. The measurements of outdoor temperature, humidity etc., were made with same infrared instrument, rather than taken continuously with meteorological station. There was no control for solar irradiance via pyranometer. Temperature measurements were only possible on roof slab, not on walls. The study focused on roof and south walls only, rather than eight cardinal directions for a reasonable estimation of temperature of any azimuth, which would be useful in terms of real-world application to any building orientation.

We did not account for the possible heat transfer through radiation between the warm panels and the roof slab as we could not measure the temperature on PVs on the same days. Nonetheless, since the panels are located just above the parapet at 1.2 to $2.0 \mathrm{~m}$ from the slab and there is natural ventilation, this effect is likely to be small or negligible.

Another, likely positive, aspect of rooftop shading is the effect that it has on the performance of the roof-mounted $A C$ units. Such setup is likely to increase the performance of the $A C$ and contribute to further energy savings, not quantified in this study.

\section{Conclusion}

This pilot study measured the effect of considering the positioning of roof PV panels to maximize shading in a common Bahraini typology of semi-detached social housing scheme. The results suggest that approximately $50 \%$ of the solar gain on the roof slab 
could be avoided with shading, and consequently the total annual energy demand of the building could be reduced by 1.7 to $7 \%$ (depending on the COP of the AC installed).

Irrespectively of the results reported, it is worth noting that this report should not be seen as an endorsement of using PVs to shade roofs. As discussed in the literature review, there are more efficient and cost-effective solutions for this. Our point here is simply that, if PVs are used, then their application could consider the maximization of shading the roof slab, in which case there is added value and therefore a lower LCOE, shorter pay back period and more favourable ROI.

Apart from the obvious advantageous decrease in reliance on fossil fuels, the ubiquitous use of PV in housing creates a spatially widespread production of energy, which could contribute to the resilience of the country's electrical supply in case of grid or power plant failure.

\section{Future Research}

Deepening the research on this topic within the climatic and building context of the region has the potential to significantly impact the energy dependence of buildings, veering the building industry and therefore contribute positively to the economy. Furthermore, advancements on the topic shall allow the local population to maintain high levels of thermal comfort while following industry standards [7] and a sustainable model of development.

Since the overall annual gain on the whole house is $493,000 \mathrm{kWh} /$ Year, studies of other components of the building envelope uncover opportunities for further reductions on solar gain. The numerical model reveals that external walls also present considerable solar exposure. The smallest wall of the Southern façade, as documented above, receives $24,465 \mathrm{kWh}$ /Year. Perhaps there is a case for the vertical cladding with solar panels, creating a double skin façade. In addition to the production of energy and the reduction of solar gain through shading, such solution could create a convection effect. The electrical efficiency and power output of PV depend linearly, though inversely, on the ambient temperature [10]. Heat causes a decrease in performance, which is a hindrance to the use of photovoltaics in the region, despite the abundance of solar radiation [11]. However, when used as the exterior layer of a double skin wall, the convection effect [12], [13] created between the two layers could cool down the panels and reduce the heat-induced loss of performance. For a truly countrywide adoption of PVs in housing, it would be desirable to investigate the performance of shading, as well as energy production, in the main cardinal directions, as to create a solid reference that 
would result in accurate energy modelling and therefore increase the confidence of the public on such architectural solutions. The solution elevated façade system could also be studied to assess energy production levels and though convection might not take place, or be weaker than with the flat system, the distance from the wall might mean less overheating and therefore less performance losses. A comprehensive study would measure the implications of shading for comfort during the winter. While shading the buildings, the presence of dark PV panels is likely to concentrate heat and therefore might contribute to the heat island effect [2], as opposed to an albedo roof. This effect should be considered on a future study. Future studies could also quantify the energy savings accrued from the likely increase in performance of $A C$ due to the shading of roof-mounted units.

If the effect of shading is of interest, it can also be used through other components (and materials), rather than PVs. Less costly boards of reflective material could be as or more effective than PVs, for a fraction of the cost. Moreover, as noticed on the literature review, painting roofs with a reflective/white coat is an even simpler and cheaper solution that can have a positive impact on energy demand for cooling. A local study of such solutions and their performance could provide accurate information on ROI for each, which could give the general public the confidence necessary to choose the solution adequate to their own circumstances, and eventually generalize the use of heat mitigating strategies, contributing to a more sustainable built environment.

\section{References}

[1] S. Tong, H. Li, K. T. Zingre, M. P. Wan, V. W. C. Chang, S. K. Wong, W. B. T. Toh, and I. Y. L. Lee, "Thermal performance of concrete-based roofs in tropical climate," Energy Build., vol. 76, pp. 392-401, 2014.

[2] D. S. Parker and S. F. Barkaszi Jr, "Roof solar reflectance and cooling energy use: field research results from Florida," Energy Build., vol. 25, no. 2, pp. 105-115, 1997.

[3] C. Romeo and M. Zinzi, "Impact of a cool roof application on the energy and comfort performance in an existing non-residential building. A Sicilian case study," Energy Build., 2013.

[4] A. Dimoudi, A. Androutsopoulos, and S. Lykoudis, "Summer performance of a ventilated roof component," Energy Build., vol. 38, no. 6, pp. 610-617, 2006.

[5] N. Zhou, W. Gao, M. Nishida, H. Kitayama, and T. Ojima, "Field study on the thermal environment of passive cooling system in RC building," Energy Build., vol. 36, no. 12, pp. 1265-1272, 2004. 
[6] R. U. Halwatura and M. T. R. Jayasinghe, "Thermal performance of insulated roof slabs in tropical climates," Energy Build., vol. 40, no. 7, pp. 1153-1160, 2008.

[7] Ansi/Ashrae, "ANSI/ASHRAE 55:2004 Thermal Environmental Conditions for Human Occupancy," Ashrae, vol. 2004, p. 30, 2004.

[8] J. Pinelo Silva, "Solar radiation and street temperature as function of street orientation. An analysis of the status quo and simulation of future scenarios towards sustainability in Bahrain," in World Renewable Energy Congress-17- E3S Web of Conferences - DOI: 10.1051/e3sconf/20172302002, 2017, vol. 23, p. 15.

[9] S. Haji, A. Durazi, and Y. Al-Alawi, "Feed-in tariff structure development for photovoltaic electricity and the associated benefits for the Kingdom of Bahrain," Int. J. Sustain. Energy, vol. o, no. 0, pp. 1-19, 2017.

[10] S. Dubey, J. N. Sarvaiya, and B. Seshadri, "Temperature dependent photovoltaic (PV) efficiency and its effect on PV production in the world - A review," Energy Procedia, vol. 33, pp. 311-321, 2013.

[11] K. Kawajiri, T. Oozeki, and Y. Genchi, "Effect of temperature on PV potential in the world," Environ. Sci. Technol., vol. 45, no. 20, pp. 9030-9035, 2011.

[12] A. Dama, D. Angeli, and O. K. Larsen, "Naturally ventilated double-skin façade in modeling and experiments," Energy Build., vol. 144, pp. 17-29, 2017.

[13] F. Marques da Silva, M. G. Gomes, and A. M. Rodrigues, "Measuring and estimating airflow in naturally ventilated double skin facades," Build. Environ., vol. 87, pp. 292$301,2015$. 